\title{
Health Status and Labour Force Participation: Evidence from Australia
}

\author{
Lixin Cai $^{\#}$ and Guyonne Kalb ${ }^{*}$ \\ Melbourne Institute of Applied Economic and Social Research \\ The University of Melbourne
}

\begin{abstract}
June 2005
Abstract

This paper examines the effect of health on labour force participation using the Household, Income and Labour Dynamics in Australia (HILDA) Survey. The potential endogeneity of health, especially self-assessed health, in the labour force participation equation is addressed by estimating the health equation and the labour force participation equation simultaneously. Taking into account the correlation between the error terms in the two equations, the estimation is conducted separately for males aged 15 to 49 , males aged 50 to 64 , females aged 15 to 49 and females aged 50 to 60 . The results indicate that better health increases the probability of labour force participation for all four groups. However the effect is larger for the older groups and for women. As for the feedback effect, it is found that labour force participation has a significant positive impact on older females' health, and a significant negative effect on younger males' health. For younger females and older males, the impact of labour force participation on health is not significant. The null-hypothesis of exogeneity of health to labour force participation is rejected for all groups.
\end{abstract}

Key words: Self-reported health, labour force participation, endogeneity of health, simultaneous equation model

\footnotetext{
\# Corresponding author: Lixin Cai, Melbourne Institute of Applied Economic and Social Research, The University of Melbourne, Melbourne VIC 3010, Australia. E-mail: cail@unimelb.edu.au, telephone: +61 38344 2094, fax: +61 383442111.

* We would like to thank John Creedy, Bob Gregory, Phil Lewis, Jenny Williams, Mark Wooden and two anonymous referees for their valuable comments and suggestions on an earlier version of this paper.

This paper is based on research being conducted as part of the research program "The Dynamics of Economic and Social Change: An Analysis of the Household, Income and Labour Dynamics in Australia Survey”. It is supported by an Australian Research Council Discovery Grant (DP0342970). The paper uses the data in the confidentialised unit record file from the Department of Family and Community Services' (FaCS) Household, Income and Labour Dynamics in Australia (HILDA) Survey, which is managed by the Melbourne Institute of Applied Economic and Social Research. The findings and views reported in the paper, however, are those of the authors and should not be attributed to either FaCS or the Melbourne Institute.
} 


\section{Introduction}

In this paper we examine the relationship between health status and labour force participation of working age men and women. One reason for being interested in this issue is that if poor health reduces labour productivity and leads to reduced labour force participation, health problems impose a cost on the economy in terms of production loss. An indication that this may be a relevant problem is the increase in the number of people who receive a social security payment associated with being disabled. A better understanding of the relationship between health and labour market activities is necessary to estimate the costs of health limitations to the economy [1-3].

As a second concern, in the context of population ageing, understanding the relationship between health and labour market behaviour of older working age people has important policy implications. With an ageing population, it becomes important to keep older working age people in the labour force for at least two reasons: (a) to contain the rapidly increasing demand for public expenditure on income support for mature-age people; and (b) to maintain sufficient supply of labour to support national production. Many developed nations have been attempting to develop policies to encourage older workers to remain active in the labour market. Clearly the success of such policies would depend on better understanding the impact of health on labour market activity, especially labour force participation, of older working age people.

An issue in studying the relationship between health and labour force status is the measurement of health in general and the potential endogeneity of self-assessed health in particular. A more objective measure of health status is less likely to be subject to the rationalisation endogeneity problem associated with self-assessed measures of health. However, even objective measures of health can be endogenous to individuals' labour market behaviours. Thus, a simultaneous equation modelling approach with two correlated equations for labour force participation and health may be more appropriate for estimating the effect of health on labour force participation than a single equation for labour force participation with health as an exogenous explanatory variable. Few researchers have used a simultaneous modelling approach. An exception is Stern [4] using binomial indicators for health and labour force participation. We follow Stern in setting up the model, but we use the full information maximum likelihood (FIML) estimation method to estimate a simultaneous model using more than two levels of 
health. For more than two levels of health, Stern used a two-stage estimation method which is less efficient.

The effect of health on labour market activities has been under extensive examination in the US and many research papers have been generated [2, 5]. The focus in the literature has been mostly on older working age (white) men and was motivated by an increase in the incidence of early retirement of older men. After an extensive review of the literature, Currie and Madrian [5] (p. 3353) conclude that "a glaring limitation of the existing literature is the intense focus on elderly white men, to the virtual exclusion of most other groups. Studies to remedy this situation would be most useful”. This paper seeks to extend the focus to a broader group. In addition, studies on this issue using Australian data are scarce. Exceptions are Wilkins [6] who looks at the impact of disability on labour supply (including employment probability and hours worked) and Brazenor [7] who examines the impact of disability on earnings. Both studies use the 1998 Survey of Disability, Ageing and Carers (SDAC) collected by the Australian Bureau of Statistics (ABS).

The disability status in SDAC is derived from a combination of long-term health conditions and specific activity restrictions. As such, it has the advantage of being more objectively measured than the self-assessed health status used in most studies in the literature. However, this definition will exclude some individuals in poor health because poor health may not necessarily manifest itself in the form of disabilities. For example, a person without any activity restriction may not be as healthy as a person with certain restrictions. In this sense, the disability definition used in SDAC may provide a narrower measure of health status than a more subjective measure.

This paper uses data from the recently released Household, Income and Labour Dynamics in Australia (HILDA) Survey. The advantage of these data is that, in addition to standard health measures, the data also contain information on the employment history of both employed and unemployed persons, which provides us with an opportunity to examine the impact of previous labour market experience on current health status and labour force participation.

The paper is arranged as follows: Section 2 briefly discusses some modelling issues regarding the relationship between health status and labour force participation and 
outlines the modelling strategy. Section 3 describes the data and model specifications. Section 4 presents the estimation results. Section 5 concludes the paper.

\section{The relationship between health and labour force participation}

\subsection{Theory}

Although the discussion here focuses on labour force participation, most of the arguments also apply to labour supply in general. A formal approach relating health and labour market behaviour treats health as human capital. Becker [8] drew an analogy between "investment" in health and in other forms of human capital such as education. This approach was further developed by Grossman [9]. See Currie and Madrian [5] for a detailed discussion. In this approach, both employees and employers value health like they value education because health and the capacity or ability to perform a job adequately are closely related. Obviously, poor health is likely to have an adverse effect on work performance and leads to lower productivity. As a result, people with poor health have a lower probability of being employed under prevailing wages. On the other hand, low productivity associated with poor health decreases individuals' earning potential, the opportunity costs of leisure and therefore their willingness to participate in the labour force. Thus, according to human capital theory, health and labour force participation (or labour supply in general) are positively correlated. That is better health is likely to lead to a higher probability of labour force participation.

However, productivity may not be the only link between health and labour supply. Onset of some health problems may change the individual's relative utility derived from income and time out of the labour market, even if these problems do not have any impact on the individual's productivity. For example, poor health may cause individuals to value time out of the labour market more since the time needed to care for one's health increases with ill health. Also, by affecting life expectancy, poor health may make withdrawal from the labour market more attractive by influencing the time horizon over which economic decisions are made [2]. Like human capital theory, these arguments predict that poor health leads to lower labour supply and a lower probability of labour force participation. Hence, the impact of health on labour supply may operate through influencing individual preferences or through influencing the ability to fulfil job requirements. The literature has not been able to discriminate between these two effects 
[2].

The above arguments suggest that poor health reduces the probability of labour force participation. However, it could also be argued that low earnings associated with poor health may have an income effect, which could then increase labour supply. In addition, poor health implies individuals may need more health services. To meet the increased demand for health services, individuals may need to work more. Therefore, theoretically, the exact direction of the effect of health on labour supply is not clear [10], although most empirical studies find a positive impact.

Theory also suggests that health may be endogenous to labour supply. This is implied in the human capital theory of health. To improve or maintain health status, individuals need to invest in their health, which requires both time and material resources. The availability of resources may depend on the individual's labour supply (past and current). In addition, labour market activities may also have a direct impact on individual health. For example, boredom or general lack of activity in non-participation may lead to a deterioration of health $[4,11]$. Alternatively, it is also possible that stress associated with employment leads to health deterioration. In addition, some jobs may have bad working conditions and are harmful to health. Thus, in theory labour force participation could also affect health, although the direction of the impact is ambiguous.

In the US, health insurance is often tied to employment. As a result, labour force participation can be particularly important for persons with health problems, who do not qualify for a disability programme. ${ }^{1}$ In Australia, similar to the situation in many European countries, all residents are covered by a public health insurance system (called Medicare). Coverage is independent of work status and the public system provides an adequate level of health care, therefore employment is not important for receiving the required level of health care. This universal coverage means that the health insurance status is unlikely to be an important factor in determining health. Additional insurance can be taken out for private health care, but this just shortens the waiting time for elective surgery and provides a choice in doctors or hospitals. This private insurance is on a voluntary basis and is not linked directly to employment.

The endogeneity just described arises from the assumption that health can be accurately

\footnotetext{
${ }^{1}$ We are grateful to an anonymous referee for pointing this out to us.
} 
measured. However, in most of the survey data, only self-assessed health is available. Therefore, in the literature most studies that have included a health measure to explain work decisions have included individuals' self-assessed health as an explanatory variable [12]. However, with regard to the use of self-assessed health in estimating the effects of health on labour supply, several researchers raise the concern that selfassessed health may be used as a rationalisation for labour force status [4, 10, 12-15]. For example, those not in the labour force may tend to report poor health to justify their non-participation. The consequence of rationalisation is that when self-assessed health is used in the labour force participation equation, the health variable becomes endogenous and the effects tend to be overestimated. This endogeneity is different from that discussed in the previous paragraph. Here the endogeneity occurs due to the use of the self-assessed health measure, whereas in the previous paragraph it was suggested that health might be endogenous to labour supply, even if a true measure of health were used. We refer to the endogeneity associated with self-assessed health as rationalisation endogeneity. Self-assessed health may also suffer from measurement errors [15], but it is the rationalisation endogeneity that raises the major concern in the literature.

To account for the potential problems associated with self-assessed health variables, some authors have used more objectively measured health such as subsequent mortality $[13,14,16]$ or specific health conditions to instrument self-assessed health $[10,15,17$, 18]. However, an objective measure of health, even if available in a dataset, is not free of problems [15]. The instrumental variable approach does not itself solve the problem of endogenous self-assessed health $[12,15]$.

\subsection{Modelling strategies}

To account for the endogeneity of health to labour force participation, we estimate the health equation and labour force participation equations simultaneously. The modelling strategies draw on Stern [4] and are briefly described in this section. The model specification is presented in the next section. The first equation describes the determination of health:

(1) $h^{* *}=\gamma_{1} l^{*}+x_{1} \beta_{1}+\varepsilon_{1}$

where $h^{* *}$ is the latent true health which depends on the latent inclination to participate 
in the labour force $\left(l^{*}\right)$ and a set of exogenous variables, $x_{1}$. Latent labour force participation enters equation (1) because of the endogeneity of true health. The rationalisation endogeneity is not accounted for in equation (1) because this equation is about the determination of true health, not self-assessed health.

The labour force participation equation is specified as

(2) $l^{*}=\gamma_{2} h^{* *}+x_{2} \beta_{2}+\varepsilon_{2}$

where the latent value of being in the labour force relative to being out of the labour force is determined by true health $h^{* *}$ and a set of exogenous variables $x_{2} \cdot x_{1}$ and $x_{2}$ may have some variables in common.

Because true health is not observed, we need another equation to relate true health and the observed self-assessed health, which is:

(3) $h^{*}=h^{* *}+\alpha l^{*}+\omega$

where $h^{*}$ is the latent measure of self-assessed health status, which depends on true health and labour force participation. The dependence of self-assessed health on labour force status reflects the rationalisation endogeneity of self-assessed health. A positive $\alpha$ implies that those in the labour force tend to overstate their health and those not in the labour force tend to understate their health. The three disturbance terms, $\varepsilon_{1}, \varepsilon_{2}$ and $\omega$, are assumed to be jointly normally distributed.

Substituting equation (1) into equation (3), gives:

(4) $h^{*}=\theta_{1} l^{*}+x_{1} \beta_{1}+\varepsilon_{h}$

where $\theta_{1}=\gamma_{1}+\alpha$, and $\varepsilon_{h}=\varepsilon_{1}+\omega$. In the model, only $\theta_{1}$ can be identified; $\gamma_{1}$ and $\alpha$ cannot be estimated separately. This means that true endogeneity and rationalisation endogeneity cannot be separated and only the total endogeneity can be estimated. However, when interpreting the $\theta_{1}$ parameter it is useful to keep the distinction between the two types of endogeneity in mind.

From (3), it follows that $h^{* *}=h^{*}-\alpha l^{*}-\omega$. Substituting this into (2) gives: 
(5) $l^{*}=\theta_{2} h^{*}+x_{2} \beta_{L}+\varepsilon_{L}$

where $\theta_{2}=\frac{\gamma_{2}}{\left(1+\gamma_{2} \alpha\right)}, \beta_{L}=\frac{\beta_{2}}{\left(1+\gamma_{2} \alpha\right)}$, and $\varepsilon_{L}=\frac{\left(\varepsilon_{2}-\gamma_{2} \omega\right)}{\left(1+\gamma_{2} \alpha\right)}$.

$\varepsilon_{h}$ and $\varepsilon_{L}$ are correlated through $\omega$, even if $\varepsilon_{1}$ and $\varepsilon_{2}$ were assumed to be independent. However, $\varepsilon_{1}$ and $\varepsilon_{2}$ are highly likely to be correlated because there may be some unobservable factors that affect both health and labour force participation.

The corresponding observed values of the endogenous variables are:

(6) $h=\left\{\begin{array}{cccc}4 & (=\text { excellent }) & \text { if } & m_{3}<h^{*}<m_{4}=+\infty \\ 3 & (=\text { very good }) & \text { if } & m_{2}<h^{*} \leq m_{3} \\ 2 & (=\text { good }) & \text { if } & m_{1}<h^{*} \leq m_{2} \\ 1 & (=\text { fair }) & \text { if } & m_{0}<h^{*} \leq m_{1} \\ 0 & (=\text { poor }) & \text { if } & -\infty=m_{-1}<h^{*} \leq m_{0}\end{array}\right.$,

where $\left(m_{0}, m_{1}, m_{2}, m_{3}\right)$ are unobserved cut-off points, and

(7) $l=\left\{\begin{array}{lll}1 \quad(=\text { in labour force }) & \text { if } l^{*}>0 \\ 0 \quad(=\text { not in labour force }) & \text { if } l^{*} \leq 0\end{array}\right.$.

Equations (4), (5), (6) and (7) constitute a simultaneous equation system. The coefficient parameters to be estimated are $\theta_{1}, \theta_{2}, \beta_{1}, \beta_{L}$ in equations (4) and (5), and $m_{0}, m_{1}, m_{2}, m_{3}$ in equation (6). To identify these coefficients, standard conditions for simultaneous equation models need to be satisfied. We implement these conditions by including different variables in $x_{1}$ and $x_{2}$. Based on (6) and (7), equation (4) is essentially an ordered probit model and equation (5) a probit model. Therefore, $\theta_{1}$ and $\beta_{1}$ can only be identified up to a factor which is the inverse of the standard deviation of $\varepsilon_{h}$. Similarly, $\theta_{2}$ and $\beta_{L}$ are identified up to a factor which is the inverse of the standard deviation of $\varepsilon_{L}[19]$.

The maximum likelihood method is used to estimate the parameters in equations (4) and (5) simultaneously. We assume that $\varepsilon_{L}$ and $\varepsilon_{h}$ follow a standard bivariate normal 
distribution with a correlation coefficient $\rho$ which is also to be estimated. Because we take into account the correlation between the error terms in the two structural equations, this method is called full information maximum likelihood (FIML) method [20]. Define

$P_{i, m n}=\operatorname{Pr}(h=m, l=n)$ for observation $i$, $d_{i, m n}=\left\{\begin{array}{ll}1 & \text { if } \quad h=m \\ 0 & \text { otherwise }\end{array} \quad\right.$ and $\quad l=n \quad$, for $h=0,1,2,3,4$ and $l=0,1$.

The log-likelihood function for the sample is

(10) $l l=\sum_{i=1}^{N} \sum_{m=0}^{4} \sum_{n=0}^{1} d_{i, m n} \log P_{i, m n}$.

Appendix 1 provides the detailed probability definitions. Standard econometric packages do not provide this type of model. Therefore, a GAUSS programme was written to estimate the model.

Although the modelling approach here is similar to Stern's [4], Stern estimates the simultaneous equations using the FIML method when both the self-assessed health variable and labour force participation variable take a dichotomous form, but when he allows the health variable to take a polychotomous form, he uses a two-stage estimation method. The two-stage method is essentially an instrumental variable method, where all exogenous variables are used as instruments to estimate each equation in the system separately (see for example, Greene [20]). The two-stage estimation method produces consistent parameter estimates, but it is not efficient because the potential correlation between the error terms in the structural equations is not taken into account.

The FIML estimation method employed in this paper explicitly takes into account the correlation between the two error terms in equations (4) and (5) and the estimation results are thus consistent as well as efficient (see econometric textbooks, such as Greene [20] or Judge et al. [21]). Another advantage of the FIML method is that the significance of the coefficient on the labour force participation variable and the correlation coefficient between the two error terms can be jointly tested. This is a true test of the exogeneity hypothesis. In contrast, in the two-stage method, exogeneity can only be partially tested. This is because in the two-stage method only the coefficient on 
the labour force participation variable is estimated and the correlation coefficient is not taken into account. Exogeneity can only be tested based on the significance of the labour force participation variable. This turns out to be important for our results.

\section{Data and model specification}

\subsection{The data}

The data used for this paper come from the first wave of the Household, Income and Labour Dynamics Australia (HILDA) Survey, which was conducted in the period between 24 August 2001 and 21 December 2001. Details of this survey are documented in Watson and Wooden [22].

The HILDA survey contains detailed information on individuals' labour market activity and history. Information relating to individual health was collected in both the personal interviews and self-completion questionnaires. In the personal interviews, a standard self-assessed health status question (5 levels scaled from poor to excellent) was first asked. Then individuals were asked whether they had a long-term condition, impairment or disability which restricted everyday activities and had lasted or was likely to last for six months or more. Specific examples of these long-term conditions were shown on a card, such as for example, limited use of fingers or arms, or problems with eye sight that could not be corrected with glasses or contact lenses. For those who had a long-term condition, impairment or disability, three follow-up questions were asked: whether the condition or disability limited the type of work or the amount of work; how much the condition or disability limited work; and whether the condition or disability first developed in the last 12 months.

In the self-completion questionnaire, the Short Form 36 health status questions (SF-36) were asked. The SF-36 is a measure of general health and wellbeing, and produces scores for eight dimensions of health [23]. The first question in the SF-36 is the same as the first health question asked in the personal interviews. Unfortunately, the responses to the same health question are not identical for all persons who provided an answer to both the personal interviews and the self-completion questionnaire. The question arises of which self-assessed health variable is to be used in the model estimation. We chose the response in the self-completion questionnaire for the following three reasons. First, individuals may be more candid to sensitive questions, such as health status, when 
filling out a self-completion form rather than being interviewed [24]. Second, in the personal interview, persons were asked several labour market related questions before being asked the health questions. The answers to the labour market questions may have had an impact on their responses to the health questions. In particular, the effect of rationalisation of self-assessed health status may be stronger in responses to the health questions asked by the interviewer than in the self-completed questionnaire. Third, the second set of responses could be more accurate in the sense that people may have learned through answering the first set of health-related questions.

The model is estimated for four separate groups: men less than 50 years old, women less than 50 years old, men aged 50 or over and women aged 50 or over. These four groups are distinguished because we expect labour force participation to be quite different for each of the groups. In addition, the factors influencing the participation decision are likely to be different as well. Before describing the variables included in the model, we tabulate the labour force status against self-assessed health status by gender and age groups in Table 1. Those who are still at school or undertaking full-time study are excluded from the sample. People over age-pension age are also excluded (male agepension age is 65; female age-pension age is in a transition phase, but at the time of the interview was 61). A positive (negative) relationship between labour force participation (non-participation) and health status appears from the simple tabulation. Specifically, the proportion of persons not in the labour force decreases with health. That is the better their health, the more likely a person is to be in the labour force. For example, while about 70 percent of males reporting poor health are not in the labour force, only 6 percent of males reporting very good health are not in the labour force. For all five selfassessed health categories, older males are more likely not to be in the labour force than younger males. Nevertheless, the positive relationship between health and labour force participation appears for both younger and older males. Females show a similar pattern, except that for all health categories, females have a lower labour force participation rate than males, which is consistent with other survey data.

\section{Table 1 about here}

A negative relationship between health and age can also be inferred from Table 1 . While about 11 percent of males aged 15 to 49 report fair or poor health, over 24 percent males aged 50 to 64 do so. Similarly, for females, about 11 percent aged 15 to 
49 report fair or poor health, while 20 percent aged 50 to 60 do so.

\subsection{Model specification}

Table 2 provides the definitions for all variables and shows in which equation they are included. The identification condition for simultaneous equation models is satisfied because a different set of independent variables is included in the two equations. That is, each equation contains some variables that do not appear in the other equation.

\section{Table 2 about here}

The variables included in the labour force participation equation are standard in the literature. However, for the health equation, some justification may be needed for the inclusion of some of the variables listed above. Age is included because it is often observed that health deteriorates with age [25]. Australian survey data show that the disability incidence rate increases with age [26]. It is also found that people aged 50 and over have a higher probability of entering the disability benefit program than people under 50 years of age [27]. It has long been noticed that health and marital status have a close relationship (see, for example, Beckett and Elliott [28], and references therein). Although there are different hypotheses about the mechanism through which this relationship is established, health is often seen to be positively correlated with being married. Education may improve health through enhanced awareness of health-related knowledge. In addition, it may serve to help control for the impact of parental socioeconomic status (SES) on an individual's health since individual educational achievement is greatly influenced by the parents' SES. Finally, education with age and age squared are key factors in the determination of an individual's wage. Since earnings from wages are only observed for labour force participants and (potential) wage is likely to influence health, we include age, age squared and education as instruments for wage in the health and labour force equations. As mentioned above, the linear age term is also expected to affect health directly.

To explain the difference in self-assessed health status between individuals, it would be ideal to have some specific and objective health indicators in the health equation, such as symptoms, types and severity of disabilities or health conditions, in addition to the more subjective and general question "In general would you say your health is excellent, 
very good, good, fair, or poor?”. Unfortunately, such detailed objective measures are not available in the HILDA survey. However, two summary indicators of health problems are available in the data and are included in the health equation. The first is the existence of long-term health conditions (health condition). This variable is included although it is self-reported, following a suggestion by Bound, Schoenbaum and Waidmann [29] that it is reasonable to treat self-reports of chronic health conditions as exogenous. Bound, Schoenbaum and Waidmann [30] argue that survey questions that are more specific and concrete should be less subjective and therefore less susceptible to the rationalisation endogeneity problems. The variable, health condition, is used here in a similar way to Stern [4]. The difference is that Stern includes a list of specific longterm health conditions in his health equation, while we only have a summary indicator. However, HILDA respondents are shown a card listing specific examples of these conditions when answering this question. The second indicator is one of the SF-36 indices, the index for physical functioning. Because this index is constructed based on individuals' answers to the questions about specific physical functioning limitations, such as for example, climbing one flight of stairs, lifting or carrying groceries, or bending, kneeling or stooping, the index can be treated as an exogenous variable. By including the above variables (which are assumed to be exogenous to labour force participation) in the health equation we are taking out the component of health that is unlikely to be influenced by current labour force participation. Controlling for these conditions will result in a better estimate of the feedback effect of labour force participation, because long-term health conditions are now taken into account, when comparing those in the labour force with those out of the labour force. There is no need to include these long-term conditions in the labour force participation equation separately as they are already captured by the health status variable.

By including the smoking, heavy drinking and the lack of physical activities variables in the health equation only, we assume that they affect labour force participation only through their impacts on health. Smoking has been used as a rate of time preference indicator [31], but for our data there is no strong indication that smoking or drinking would affect labour force participation except indirectly through health. Appendix 2 shows that labour force participants are slightly less likely to be a smoker or heavy drinker, although the difference is nearly non-existent for some groups. The relationship of smoking and heavy drinking with health is much stronger. 
The impact of unemployment on health has been discussed frequently [32, 33] and is included here as well. The inclusion of the employment history variable can also be justified in theory although its effect is not predicted unambiguously. On the one hand, employment may put stress on individuals or bad work conditions may be harmful to health; on the other hand, employment may make people happier and enhance selfconfidence which could have a positive effect on health. In addition, wealth and income, which are important factors in health determination, depend to some extent on employment experience. Family income and wealth also depend on the spouse's employment and furthermore the spouse's participation in the labour force may release pressure from the individual. Therefore, the spouse's labour force participation could have an impact on an individual's health status. The occupation variables are included to control for impacts of "bad" jobs on health. The variable, never worked, is included to indicate those who have never worked and have therefore no an occupation. Although occupation may be thought to affect the probability of unemployment, it is unlikely to affect labour force participation, except through the job quality component. In addition, those who have never worked are all out of the labour force and could not be included in the model if this group of variables were included in the labour force participation equation. Therefore, the occupation variables are only included in the health equation, but age, age squared and education are already included as instruments for wage and it is assumed that these variables also control for the job quality aspect of occupation. If this assumption is wrong and the error term of the labour force participation equation still contains unobserved (potential) job quality, then the effect of health on labour force participation is expected to be overestimated due to the correlation between health and unobserved job quality.

There are a few variables in the labour force participation equation which are not included in the health equation. These are being an immigrant and the presence of children. Firstly, being an immigrant, especially from a non-English speaking background, may affect labour force participation through language or cultural problems but it is unlikely to affect health if subgroups of countries of origin, with for example poor health care or different propensities for diseases, cannot be distinguished. For aggregate groups of immigrants, the overall effect may be small, given that the effect for individuals from different countries may offset each other. In addition, as the duration since the immigrant's arrival in Australia increases, their health status will 
become more similar to the health status of individuals born in Australia. Similarly having children interacted with married/de facto status is likely to affect labour force participation, particularly of women, but it is not likely to affect an individual's health status in a specific direction.

Table 3 presents variable means for the samples used in the analysis. As implied earlier, we estimate the model for males and females separately; and each gender is divided into two age groups: those aged 15 to 49 and those aged 50 to age-pension age. Therefore, the sample means are presented for these four groups. The sample used for estimation is smaller than that presented in Table 1 because individuals who have a missing value in any of the variables included in the model are excluded.

\section{Table 3 about here}

Several prominent points appear from the descriptive statistics. The participation rate of older men is about one quarter lower than that of younger men, whereas the difference between older and younger women is smaller. As expected, for both men and women, the mean value of self-assessed health is lower for older people than for younger people. Very few older people have children under the age of 4. For both older men and women, a larger proportion is born overseas than for younger men and women. In general, younger people are more educated than older people. Women are more likely to have a degree than men are, but they are less likely to have other non-degree post-school qualifications than men are. Older women are more likely to have dropped out of school than older men. Men are more likely to be tradespersons or production and transport workers than women, while women are more likely to be clerical, sales or service workers than men. For younger individuals, spouses of women are more likely to be in the labour force than spouses of men. Although smoking is still dominated by men, the difference between younger men and women is very small. While older men are more likely to be smokers than younger men, younger women are more likely to be smokers than older women. Older men are more likely to have long-term health problems than older women. Heavy drinking is more likely among younger men than any other group.

\section{Empirical results}

\subsection{FIML results for a simultaneous model of labour force participation and health}


Table 4 presents the estimation results for the four groups. The model is similar to a bivariate probit model, where the log-likelihood function is not globally concave because of the correlation coefficient between the two error terms [34]. As a result, the choice of the starting values for the parameters becomes important. Following suggestions by Maddala [19] and Greene [34], we use the estimates from the two-stage method as starting values since they are consistent estimates. The magnitude of the coefficients is not directly comparable across groups because, as mentioned earlier, the coefficients are only identified up to a factor and the factors for different groups may not be the same. From Table 4, it can be seen that in general the significant exogenous variables have the expected sign. Cai and Kalb [35] provide a more extensive discussion of the results including the effects of the exogenous variables. In this paper, we focus our discussion on the estimates for the endogenous variables health and labour force participation.

\section{Table 4 about here}

Examining the labour force participation equation (equation 5) first, a significant impact of health on labour force participation is estimated. The positive sign indicates that, other things equal, better health increases the probability of labour force participation for all four groups. Due to the endogeneity of health (independent of whether this is due to rationalisation endogeneity or true endogeneity), we cannot calculate the marginal effect of health on labour force participation. To get a feeling for the effect, we predict the probabilities of labour force participation conditional on being in one of five ranges of latent health. The five ranges of latent health are defined by the estimates for the cutoff points in the health equation and correspond to the five health categories. The reported conditional probabilities in Table 5 are averages over the sample.

\section{Table 5 about here}

Table 5 shows that the impact of health on labour force participation is larger for older people than for younger ones. For instance, for an older man a deterioration of health from good to fair reduces the probability of labour force participation by nearly 7 percent. For a younger man, the same change in health reduces the probability of labour force participation by less than 1 percent. The differences in the effect of health on labour force participation between older and younger people are as expected. It also 
appears that for the same age group the impact is somewhat larger for females than for males. This is also according to expectations.

We also computed the conditional probabilities of labour force participation by observed self-assessed health status. As expected, we found that the conditional probabilities increase with observed health status, indicating that those who have better health also have other individual or household characteristics that increase the probability of labour force participation.

Turning to the second equation in the model (equation 4), we find that the feedback effect of labour force participation on health, represented by $\theta_{1}$, is not so clear. For younger males, labour force participation is estimated to have a significant negative impact on health status, but the estimated impact is not significant for older males and younger females. For older females the estimated effect of labour force participation on health is positive and significant. In the following we interpret these feedback effects in the light of the two types of endogeneity identified in Section 2.2: true endogeneity and rationalisation endogeneity. Rationalisation endogeneity of self-assessed health to labour force participation implies that in the health equation the coefficient on labour force participation would be positive. The negative sign of $\theta_{1}$ for males and younger females suggests that the rationalisation endogeneity, if it exists, may be small and outweighed by the effects of other factors. Specifically, the significant and negative impact of labour force participation on younger males' health suggests that "bad work conditions" or "work stress" effects dominate other positive effects of labour force participation. This finding is similar to Stern [4]. The insignificance of the negative impact of labour force participation on health for older males may be due to a selfselection process: those older males who choose to remain in the labour force may have a position which has little or no "bad work conditions" effect; or they are so healthy that the "bad work conditions" or "work stress" effect does not have an adverse impact on their health.

The positive sign of the labour force participation variable in the health equation for older females indicates that rationalisation endogeneity may occur for older females' self-assessed health. This is a surprising result because women are normally under less pressure socially than men to attribute non-participation to ill health. Indeed, using data 
from the National Survey of Families and Households and from the Survey of Income and Program Participation, Ettner [36] finds that among women, self-assessed measures of health are not affected by employment status. Therefore, the positive sign for older females may not be due to rationalisation endogeneity. Rather, this may be due to selfselection into labour force status and the selection of jobs by older women. That is those older women who are in the labour force are in very good health and they have jobs that are less likely to harm their health.

The above results are similar to what is found in the literature, as discussed by Cai and Kalb [35]. Although there is a rationalisation endogeneity concern over self-assessed health, the empirical evidence on its existence is neither strong nor consistent with the hypothesis. As a result, the use of self-assessed health in estimating the effect of health on labour force participation is still popular in the literature.

The estimated correlation between the two equations, $\rho$, is negative significant for women and insignificant for men. This indicates that for women there may exist unobserved characteristics, which increase labour force participation but decrease health status. For example, ambition may increase the probability of participation, while at the same time making these women more vulnerable to stress-related health problems by trying to combine the demands of a successful high-level career with family responsibilities. The latter is often less important for men.

For older men and women, the direct effect from labour force participation and the correlation work in opposite directions (although insignificantly for men) similar to the effects in Stern [4]. This means the direction of the bias on the health coefficient in the participation equation caused by endogeneity is undetermined. However, the coefficients on health are smaller in the two-stage method and in the FIML where $\rho$ is restricted to zero than in the unrestricted FIML, which indicates a downward bias to zero. For younger men and women, the two effects work in the same direction, causing a bias towards zero of the health coefficient.

\subsection{Test for exogeneity of health in the labour force participation equation}

The model in the previous section allows for a feedback effect of labour force participation on health. This takes into account the potential endogeneity of health in the labour force participation equation. If health were not endogenous, a simpler single- 
equation model could have been estimated for labour force participation, including health as an exogenous variable. Therefore, in this subsection, we test for the endogeneity of health to check whether the more complex approach is needed.

If self-assessed health were exogenous to labour force participation, both the coefficient on the labour force participation variable in the health equation $\left(\theta_{1}\right)$ and the correlation coefficient between $\varepsilon_{h}$ and $\varepsilon_{L}(\rho)$ would be zero. Hence, the null hypothesis for exogeneity is

$$
\begin{aligned}
& H_{0}: \theta_{1}=0, \text { and } \rho=0 ; \\
& H_{A}: \theta_{1} \neq 0, \text { or } \rho \neq 0 .
\end{aligned}
$$

The Wald-test statistics for testing the joint significance of $\theta_{1}$ and $\rho$ are reported in Table 6. For the older male group, although $\theta_{1}$ and $\rho$ are not significant individually, they are jointly significant. Overall, the test results show that for all four groups, the exogeneity hypothesis is rejected. This means that health is rightly treated as an endogenous variable in the labour force participation equation. This result is quite different from the two-stage estimation, where, based on the significance of the coefficient on the labour force participation variable in the health equation, the exogeneity hypothesis is rejected for older females only.

\section{Table 6 about here}

\subsection{Comparing estimates using FIML and the two-stage method}

To compare the results from the two-stage method with the FIML method, we also carried out the two-stage estimation. Table 7 summarises the estimated effects for the main variables of interest using the two approaches. The full two-stage results are not reported in this paper, but can be found in Cai and Kalb [35].

\section{Table 7 about here}

A surprising difference between the results from the two estimation methods is the labour force participation variable in the health equation for younger males. While the variable is significant in the FIML estimation, the two-stage method produces a coefficient which is insignificant and much smaller in magnitude. The insignificance of 
the labour force participation variable in the two-stage method could be due to the lower efficiency of the estimation method. The lower efficiency could be most apparent for young males because of the lack of variation in the predicted value for the labour force participation variable in this group. The predicted value is calculated from the firststage estimation of the reduced-form labour force participation equation using probit. A feature of the probit model is that it tends to overpredict the event which is dominant in the sample. As shown in Table 3, 94 percent of younger males are in the labour force. The predicted participation rate from the first-stage estimation is even higher. As a result, the variation of the predicted value for the labour force participation variable is small (the variation coefficient, which equals the standard deviation divided by the mean value, of the predicted value for the labour force participation variable is much smaller for younger males than for the other three groups). This makes it difficult to identify its effect in the second stage. In contrast, the FIML method does not depend on the predicted value for labour force participation. This suggests that the FIML estimation method may be more appropriate to study the relationship between health and labour force participation for some groups, where efficiency of the estimation method is likely to be more important.

\subsection{Comparison to other studies}

In the literature, the estimated effects of health on labour force participation are quite different across studies. This is mainly because authors use different measures of health. A summary on the measures used in different studies on the effects of health on labour participation in the US is provided in Currie and Madrian [5] (p. 3334). This situation makes comparison between studies difficult. In addition, the majority of other studies in the literature used a dichotomous disability status as the measure of health, while in this paper the health variable takes a polychotomous form. Stern [4] used a dichotomous and a polychotomous measure of health, but his scale when the health variable takes the polychotomous form is different from the scale used in this paper. In addition, his results came from the two-stage method and his samples are different from our samples. In his two samples, one for the group aged between 25 and 60 and the other for the group aged between 25 and 65, he pooled data on males and females in estimation. Therefore, our results on the impacts of health on labour force participation are not directly comparable with Stern's [4]. However, in terms of the health endogeneity issue, 
we have a similar finding to Stern. The direction of the bias from endogeneity is opposite to the hypothesis in the literature, especially for the case of younger males. That is, there is a negative feedback effect of labour force participation on health.

It is also worth noting that Stern [4] only found the existence of endogeneity in his estimation using the FIML method. The fact that he did not find evidence of endogeneity when health takes a polychotomous form might be because he used the two-stage estimation method which ignores the correlation between the two error terms in the structural equations.

The relationship between health and labour force participation appears to be different in different age-gender groups. Stern [4] did not estimate the model separately for different age-gender groups. When we pooled the four groups, the labour force participation variable was not significant in the health equation when using the two-stage method, indicating exogeneity cannot be rejected. However, when we used the FIML method for the pooled sample, the joint test showed that exogeneity hypothesis was rejected, even though the coefficient on the labour force participation variable was insignificant. These may suggest that the weak evidence of exogeneity in Stern [4] is due to his use of the two-stage estimation method.

\section{Conclusion}

This paper has examined the relationship between health and labour force participation using the Australian HILDA Survey. The potential endogeneity of the self-assessed health variables in the labour force participation equation is addressed by estimating the health equation and the labour force participation equation simultaneously. We take into account the correlation between the error terms in the two equations to obtain an efficient result. The estimation is conducted separately for males aged 50 to 64, males aged 15 to 49 , females aged 50 to 60 and females aged 15 to 49 .

Allowing for the endogeneity of health to labour force participation does not change the positive effect of health on labour force participation, which is found in other studies. This effect is found for all four groups. Also as expected, the predicted effect of health on labour force participation is larger for older people than for younger ones. Therefore, poor health is likely to reduce productivity and although health also affects younger individuals, this effect is more important for older people and for women. This is clearly 
shown by Table 5 in this paper, where the probability of labour force participation is predicted conditional on having a specific level of health. The estimation of one model using pooled data would have disguised this diversity.

However, the rationalisation endogeneity of health status to labour force participation is not confirmed by the results in this paper. In the health equation, the labour force participation variable is not significant for older males and younger females; it is only significant for younger males and older females. In the case of younger males, the sign of the labour force participation variable is opposite to the rationalisation hypothesis in the literature, which is a similar finding to Stern's [4]. A joint test for the significance of the labour force participation variable and the correlation coefficient between the two error terms indicates that exogeneity is rejected for all four groups. Therefore, although rationalisation endogeneity of self-assessed health is not a big issue for young females and males, the existence of other sources of endogeneity may still bias the estimated effect of health on labour force participation if health is treated as an exogenous variable.

We also find that, when the labour force participation equation and the health equation are treated as a simultaneous system, the two-stage estimation method and the FIML method can produce quite different results. In particular, while the two-stage method produces an insignificant coefficient on the labour force participation variable in the health equation for younger males, the FIML method produces a significant coefficient, which is also bigger in magnitude. A possible explanation for this is that the two-stage method relies on predicted values for the endogenous variables. The insignificance of the labour force participation variable in the two-stage method could be due to the lower efficiency of this estimation method. The lower efficiency in the two-stage method is exacerbated by the lack of variation in the predicted value for the labour force participation variable for young males. In addition to being more efficient than the twostage method, FIML allows a joint test of the exogeneity hypothesis. For these reasons, the FIML method and the two-stage approach may lead to different conclusions in some circumstances, such as in this case. For example, using the two-stage approach the null hypothesis of exogeneity could not be rejected for younger women and men, whereas it was rejected when using FIML. 


\section{References}

1. Chirikos TN. Accounting for the Historical Rise in Working-Disability Prevalence. Milbank Q 1986; 64(2): 271-301.

2. Chirikos TN. The Relationship between Health and Labor Market Status. Annu Rev Public Health 1993; 14: 293-312.

3. Haveman RH, Wolfe B, Buron L, Hill S. Productivity Losses from Health/Disability in the United States from 1973-1983: An Earning Capacity Approach. Paper presented at the Annual Meeting of the American Economic Association, New Orleans; 1992.

4. Stern S. Measuring the Effect of Disability on Labour Force Participation. J Hum Resour 1989; 24(3): 361-395.

5. Currie J, Madrian BC. Health, Health Insurance and the Labor Market. In Handbook of Labor Economics, Ashenfelter O, Card D (eds). Elsevier Science B.V. 3, 1999: 3310-3415.

6. Wilkins R. Labour Market Outcomes and Welfare Dependence of Persons with Disabilities in Australia. Melbourne Institute Working Paper No. 2/03, The University of Melbourne, 2003.

7. Brazenor R. Disabilities and Labour Market Earnings in Australia. Australian Journal of Labour Economics 2002; 5(3): 319-334.

8. Becker GS. Human Capital. Columbia University Press: New York, 1964.

9. Grossman M. On the Concept of Health Capital and the Demand for Health. J Polit Econ 1972; 80: 223-255.

10. Dwyer DS, Mitchell OS. Health Problems as Determinants of Retirement: Are SelfRated Measures Endogenous? J Health Econ 1999; 18: 173-193.

11. Sickles R, Taubman P. An Analysis of the Health and Retirement Status of the Elderly. Econometrica 1986; 54: 1339-1356.

12. Kreider B. Latent Work Disability and Reporting Bias. J Hum Resour 1999; 34(4): 734-769.

13. Anderson KH, Burkhauser RV. The Importance of the Measure of Health in 
Empirical Estimates of the Labour Supply of Older Men. Econ Lett 1984; 16: 375380.

14. Anderson KH, Burkhauser RV. The Retirement-Health Nexus: A New Measure of an Old Puzzle. J Hum Resour 1985; 20(3): 321-330.

15. Bound J. Self-Reported Versus Objective Measures of Health in Retirement Models. J Hum Resour 1991; 26(1): 106-138.

16. Parsons D-O. The Male Labour Force Participation Decision: Health, Reported Health, and Economic Incentives. Economica 1982; 49(193): 81-91.

17. Bound J, Schoenbaum M, Stinebrickner TR, Waidmann T. The Dynamic Effects of Health on the Labour Force Transitions of Older Workers. Labour Economics 1999; 6: $179-202$.

18. Campolieti M. Disability and the Labor Force Participation of Older Men in Canada. Labour Economics 2002; 9: 405-432.

19. Maddala G. Limited Dependent and Qualitative Variables in Econometrics. Cambridge University Press: New York, 1983.

20. Greene WH. Econometric Analysis (Second Edition). Macmillan Publishing Company: New York, 1993.

21. Judge GJ, Hill RC, Griffiths WE, Lütkepohl H, Lee T-C. Introduction to the Theory and Practice of Econometrics. John Wiley \& Sons: New York, 1982.

22. Watson N, Wooden M. The Household, Income and Labour Dynamics in Australia (Hilda) Survey: Wave 1 Survey Methodology. HILDA Project Technical Paper Series No 1/02. Melbourne Institute of Applied Economics and Social Research, The University of Melbourne, 2002.

23. Ware J, Snow K, Kosinski M, Gandek B. Sf_36 Health Survey: Manual and Interpretation Guide. Quality Metric Incorporated: Lincoln, RI, 2000.

24. Tourangeau R, Smith TW. Asking Sensitive Questions the Impact of Data Collection Mode, Question Format, and Question Context. Public Opin Q 1996; 60: 275-304.

25. Kenkel DS. Should You Eat Breakfast? Estimates from Health Production Functions. Health Econ 1995; 4: 15-29. 
26. Australian Bureau of Statistics (ABS). Disability, Ageing and Carers Survey (1998). ABS 4430.0. Canberra, 1998.

27. Cai L, Gregory RG. Inflows, Outflows and the Growth of the Disability Support Pension (DSP) Program. Australian Social Policy 2003; 2002-2003: 121-143.

28. Beckett MK, Elliott MN. Does the Association between Marital Status and Health Vary by Sex, Race and Ethnicity? RAND Working Paper Series 02-08; 2002.

29. Bound J, Schoenbaum M, Waidmann T. Race and Education Differences in Disability Status and Labor Force Attachment in the Health and Retirement Survey. J Hum Resour 1995; 30(0): 227-267.

30. Bound J, Schoenbaum M, Waidmann T. Race Difference in Labor Force Attachment and Disability Status. Gerontologist 1996; 36(3): 311-321.

31. Barsky RB, Juster FT, Kimball MS, Shapiro MD. Preference Parameters and Behavioral Heterogeneity: An Experimental Approach in the Health and Retirement Study. Q J Econ 1997; May: 537-579.

32. Wilson SH, Walker GM. Unemployment and Health: A Review. Public Health 1993; 107: 153-162.

33. Mathers C, Schofield D. The Health Consequences of Unemployment: The Evidence. Med J Aust 1998; 168: 178-182.

34. Greene WH. Limdep Version 7.0 User Menu. Econometric Software Inc.: New York, 1995.

35. Cai L, Kalb G. Health Status and Labour Force Participation: Evidence from the HILDA Data. Melbourne Institute Working Paper No. 4/04; The University of Melbourne, 2004.

36. Ettner S. Is Working Good for You? Evidence on the Endogeneity of Mental and Physical Health to Female Employment. Unpublished paper (Harvard School of Public Health), 1997. 


\section{Appendix 1: Probability definitions}

This appendix presents the detailed probability expressions to be used in the construction of the likelihood function.

The reduced forms of equations (4) and (5) can be written as:

$$
\begin{aligned}
& h^{*}=\frac{1}{1-\theta_{1} \theta_{2}}\left[x_{1} \beta_{1}+x_{2} \beta_{L} \theta_{1}+\left(\varepsilon_{h}+\theta_{1} \varepsilon_{L}\right)\right]=x^{*} \pi_{1}+\varepsilon_{1}^{*}, \text { and } \\
& l^{*}=\frac{1}{1-\theta_{1} \theta_{2}}\left[x_{1} \beta_{1} \theta_{2}+x_{2} \beta_{L}+\left(\varepsilon_{L}+\theta_{2} \varepsilon_{h}\right)\right]=x^{*} \pi_{2}+\varepsilon_{2}^{*}
\end{aligned}
$$

where $\left.x^{*} \pi_{1}=\frac{1}{1-\theta_{1} \theta_{2}}\left[x_{1} \beta_{1}+x_{2} \beta_{L} \theta_{1}\right)\right], \varepsilon_{1}^{*}=\frac{1}{1-\theta_{1} \theta_{2}}\left(\varepsilon_{h}+\theta_{1} \varepsilon_{L}\right)$,

$$
\left.x_{2}^{*} \pi_{2}=\frac{1}{1-\theta_{1} \theta_{2}}\left[x_{1} \beta_{1} \theta_{2}+x_{2} \beta_{L}\right)\right] \text {, and } \varepsilon_{2}^{*}=\frac{1}{1-\theta_{1} \theta_{2}}\left(\varepsilon_{L}+\theta_{2} \varepsilon_{h}\right) \text {. }
$$

Due to the terms, $\varepsilon_{L}$ and $\varepsilon_{h}$, the covariance of the two error terms in the reduced-form equations, $\varepsilon_{1}^{*}$ and $\varepsilon_{2}^{*}$, is determined by assumptions on $\varepsilon_{L}$ and $\varepsilon_{h}$. We assume $\varepsilon_{L}$ and $\varepsilon_{h}$ to follow a standard normal bivariate distribution with a correlation coefficient $\rho$. Then $\varepsilon_{1}^{*}$ and $\varepsilon_{2}^{*}$ follow $N(0, \Omega)$, where

$$
\Omega=\left[\begin{array}{cc}
1 & -\theta_{1} \\
-\theta_{2} & 1
\end{array}\right]^{-1}\left[\begin{array}{cc}
1 & \rho \\
\rho & 1
\end{array}\right]\left(\left[\begin{array}{cc}
1 & -\theta_{1} \\
-\theta_{2} & 1
\end{array}\right]^{-1}\right)^{T}
$$

Denote the variances of $\varepsilon_{1}^{*}$ and $\varepsilon_{2}^{*}$ by $\sigma_{1}^{2}$ and $\sigma_{2}^{2}$, respectively, and their correlation coefficient by $\rho^{*}$, then the probabilities are as follows:

Probability of poor health and non-participation:

$$
P_{00}=\operatorname{Pr} o b(h=0, l=0)=\Phi_{2}\left(\left(m_{0}-x^{*} \pi_{1}\right) / \sigma_{1}, \quad\left(-x^{*} \pi_{2}\right) / \sigma_{2}, \rho^{*}\right) .
$$

Probability of poor health and participation:

$$
P_{01}=\operatorname{Pr} o b(h=0, l=1)=\Phi\left(\left(m_{0}-x^{*} \pi_{1}\right) / \sigma_{1}\right)-\Phi_{2}\left(\left(m_{0}-x^{*} \pi_{1}\right) \sigma_{1}, \quad\left(-x^{*} \pi_{2}\right) / \sigma_{2}, \quad \rho^{*}\right) \text {. }
$$


Probability of fair, good or very good health (i.e., $\mathrm{i}=1,2$ and 3 respectively) and nonparticipation:

$P_{i 0}=\Phi_{2}\left(\left(m_{i}-x^{*} \pi_{1}\right) / \sigma_{1}, \quad\left(-x^{*} \pi_{2}\right) / \sigma_{2}, \quad \rho^{*}\right)-\Phi_{2}\left(\left(m_{i-1}-x^{*} \pi_{1}\right) / \sigma_{1}, \quad\left(-x^{*} \pi_{2}\right) / \sigma_{2}, \rho^{*}\right)$.

Probability of fair, good or very good health and participation:

$$
\begin{aligned}
P_{i 1}= & \Phi\left(\left(m_{i}-x^{*} \pi_{1}\right) / \sigma_{1}\right)-\Phi\left(\left(m_{i-1}-x^{*} \pi_{1}\right) / \sigma_{1}\right)-\Phi_{2}\left(\left(m_{i}-x^{*} \pi_{1}\right) / \sigma_{1}, \quad\left(-x^{*} \pi_{2}\right) / \sigma_{2}, \quad \rho^{*}\right) \\
& +\Phi_{2}\left(\left(m_{i-1}-x^{*} \pi_{1}\right) / \sigma_{1}, \quad\left(-x^{*} \pi_{2}\right) / \sigma_{2}, \quad \rho^{*}\right) .
\end{aligned}
$$

Probability of excellent health and non-participation:

$$
P_{40}=\Phi\left(\left(-x^{*} \pi_{2}\right) / \sigma_{2}\right)-\Phi_{2}\left(\left(m_{3}-x^{*} \pi_{1}\right) / \sigma_{1}, \quad\left(-x^{*} \pi_{2}\right) / \sigma_{2}, \rho^{*}\right) .
$$

Probability of excellent health and participation:

$$
P_{41}=1-\Phi\left(\left(m_{3}-x^{*} \pi_{1}\right) / \sigma_{1}\right)-\Phi\left(\left(-x^{*} \pi_{2}\right) / \sigma_{2}\right)+\Phi_{2}\left(\left(m_{3}-x^{*} \pi_{1}\right) / \sigma_{1}, \quad\left(-x^{*} \pi_{2}\right) / \sigma_{2}, \rho^{*}\right) .
$$

Where $\Phi$ is the univariate standard normal distribution function and $\Phi_{2}$ the bivariate standard normal distribution function. $\sigma_{1}^{2}, \sigma_{2}^{2}$ and $\rho^{*}$ are functions of $\theta_{1}, \theta_{2}$ and $\rho$. 
Appendix 2: Smoking and heavy drinking cross tabulations

\begin{tabular}{|c|c|c|c|c|c|}
\hline $\begin{array}{l}\text { Labour force } \\
\text { participation: }\end{array}$ & $\begin{array}{r}\text { Non- } \\
\text { smoker }\end{array}$ & Smoker & $\begin{array}{r}\text { Non- } \\
\text { heavy } \\
\text { drinker }\end{array}$ & $\begin{array}{l}\text { Heavy } \\
\text { drinker }\end{array}$ & No. obs \\
\hline \multicolumn{6}{|l|}{ Males 15-49 } \\
\hline \multirow{2}{*}{$\begin{array}{l}\text { Non-participant } \\
\text { participant }\end{array}$} & 32.26 & 67.74 & 79.57 & 20.43 & 186 \\
\hline & 44.96 & 55.04 & 85.38 & 14.62 & 3,003 \\
\hline \multicolumn{6}{|l|}{ Males 50-64 } \\
\hline \multirow{2}{*}{$\begin{array}{l}\text { Non-participant } \\
\text { participant }\end{array}$} & 27.57 & 72.43 & 92.96 & 7.04 & 341 \\
\hline & 41.08 & 58.92 & 95.57 & 4.43 & 835 \\
\hline \multicolumn{6}{|l|}{ Females 15-49 } \\
\hline \multirow{2}{*}{$\begin{array}{l}\text { Non-participant } \\
\text { participant }\end{array}$} & 45.41 & 54.59 & 94.82 & 5.18 & 850 \\
\hline & 50.9 & 49.1 & 95.16 & 4.84 & 2,560 \\
\hline \multicolumn{6}{|l|}{ Females 50-60 } \\
\hline \multirow{2}{*}{$\begin{array}{l}\text { Non-participant } \\
\text { participant }\end{array}$} & 53.63 & 46.37 & 99.16 & 0.84 & 358 \\
\hline & 57.04 & 42.96 & 98.97 & 1.03 & 582 \\
\hline \multicolumn{6}{|l|}{ Health status: } \\
\hline \multicolumn{6}{|l|}{ Males 15-49 } \\
\hline Poor & 25 & 75 & 85.42 & 14.58 & 48 \\
\hline Fair & 32.3 & 67.7 & 82.47 & 17.53 & 291 \\
\hline Good & 38.84 & 61.16 & 83.58 & 16.42 & 1,017 \\
\hline Very good & 46.88 & 53.12 & 85.85 & 14.15 & 1,265 \\
\hline Excellent & 55.63 & 44.37 & 87.15 & 12.85 & 568 \\
\hline \multicolumn{6}{|l|}{ Males 50-64 } \\
\hline Poor & 15 & 85 & 98.75 & 1.25 & 80 \\
\hline Fair & 29.38 & 70.62 & 92.27 & 7.73 & 194 \\
\hline Good & 34.43 & 65.57 & 93.67 & 6.33 & 395 \\
\hline Very good & 45.09 & 54.91 & 96.29 & 3.71 & 377 \\
\hline Excellent & 47.69 & 52.31 & 95.38 & 4.62 & 130 \\
\hline \multicolumn{6}{|l|}{ Females 15-49 } \\
\hline Poor & 25.37 & 74.63 & 94.03 & 5.97 & 67 \\
\hline Fair & 38.16 & 61.84 & 93.42 & 6.58 & 304 \\
\hline Good & 42.79 & 57.21 & 94.48 & 5.52 & 1,033 \\
\hline Very good & 52.79 & 47.21 & 95.54 & 4.46 & 1,345 \\
\hline Excellent & 61.12 & 38.88 & 95.92 & 4.08 & 661 \\
\hline \multicolumn{6}{|l|}{ Females 50-60 } \\
\hline Poor & 44.74 & 55.26 & 97.37 & 2.63 & 38 \\
\hline Fair & 48.15 & 51.85 & 97.78 & 2.22 & 135 \\
\hline Good & 54.09 & 45.91 & 99.37 & 0.63 & 318 \\
\hline Very good & 58.05 & 41.95 & 99.39 & 0.61 & 329 \\
\hline Excellent & 65.83 & 34.17 & 99.17 & 0.83 & 120 \\
\hline
\end{tabular}


Appendix for referees' information: Two-stage estimation results

\begin{tabular}{|c|c|c|c|c|}
\hline & \multicolumn{2}{|c|}{ Males 15-49 } & \multicolumn{2}{|c|}{ Females 15-49 } \\
\hline & Coefficient & Standard error ${ }^{(\mathrm{a})}$ & Coefficient & Standard error \\
\hline \multicolumn{5}{|c|}{ Labour force participation equation } \\
\hline health & $0.7467 * * *$ & 0.0821 & $0.3581 * * *$ & 0.0486 \\
\hline age/10 & -0.0684 & 0.2836 & $-0.7227 * * *$ & 0.2040 \\
\hline age squared/100 & -0.0242 & 0.0679 & $0.1600 * * *$ & 0.0507 \\
\hline degree & $0.5142 * * *$ & 0.1833 & $0.5640 * * *$ & 0.0901 \\
\hline other post-sch qual & 0.0567 & 0.1097 & $0.2085^{* * *}$ & 0.0715 \\
\hline completed year 12 & 0.2695 & 0.1873 & 0.0452 & 0.0932 \\
\hline married & $-0.2765 *$ & 0.1664 & $-0.5500 * * *$ & 0.1579 \\
\hline spouse in labour force & $0.4693 * * *$ & 0.1415 & $0.4545 * * *$ & 0.1467 \\
\hline employment history & $2.6089 * * *$ & 0.2495 & $2.1250 * * *$ & 0.1180 \\
\hline unemployment history & $1.8403^{* * *}$ & 0.3119 & $1.1233^{* * *}$ & 0.2462 \\
\hline indigenous & 0.1189 & 0.2850 & 0.0811 & 0.2151 \\
\hline born overseas & -0.1819 & 0.1523 & -0.1365 & 0.1015 \\
\hline born non-En country & 0.1768 & 0.2223 & 0.0103 & 0.1275 \\
\hline child 0-4 & $-1.9401 * * *$ & 0.6855 & $-1.0110 * * *$ & 0.1484 \\
\hline child 5-14 & -0.4292 & 0.2689 & $-0.3010 * * *$ & 0.1147 \\
\hline married*child 0-4 & $2.2108 * * *$ & 0.7016 & -0.2022 & 0.1650 \\
\hline married*child 5-14 & $0.5793 *$ & 0.2986 & $0.4184 * * *$ & 0.1304 \\
\hline constant & $-1.2563 * * *$ & 0.2845 & -0.3066 & 0.1899 \\
\hline Number of observations & & 3189 & & 340 \\
\hline Log likelihood & & -437.39 & & -1296.97 \\
\hline \multicolumn{5}{|l|}{ Health equation } \\
\hline Labour force & -0.0301 & 0.1054 & 0.0113 & 0.0368 \\
\hline age/10 & -0.0966 & 0.1148 & $0.2419 *$ & 0.1242 \\
\hline age squared/100 & -0.0074 & 0.0282 & $-0.0775 * *$ & 0.0305 \\
\hline degree & $0.3142^{* * *}$ & 0.0944 & $0.1807 * * *$ & 0.0652 \\
\hline other post-sch qual & $0.1267^{* *}$ & 0.0559 & $0.1250 * *$ & 0.0530 \\
\hline completed year 12 & $0.2072^{* *}$ & 0.0862 & $0.1824 * * *$ & 0.0668 \\
\hline married & -0.0270 & 0.0601 & 0.0840 & 0.1039 \\
\hline spouse in labour force & $0.1466 * *$ & 0.0738 & 0.0515 & 0.0977 \\
\hline employment history & 0.4454 & 0.3198 & $0.2150^{*}$ & 0.1178 \\
\hline unemployment history & 0.1404 & 0.2787 & -0.0759 & 0.2130 \\
\hline indigenous & $0.4828 * *$ & 0.1983 & -0.0652 & 0.1586 \\
\hline smoker & $-0.2057 * * *$ & 0.0422 & $-0.2911^{* * *}$ & 0.0387 \\
\hline lack physical activity & $-0.3188 * * *$ & 0.0508 & $-0.4017 * * *$ & 0.0426 \\
\hline heavy drinker & $-0.1379 * *$ & 0.0631 & 0.0665 & 0.0970 \\
\hline health condition & $-0.7299 * * *$ & 0.0998 & $-0.8829 * * *$ & 0.0680 \\
\hline physical functioning/100 & $1.4002^{* * *}$ & 0.1919 & $1.6664^{* * *}$ & 0.1520 \\
\hline tradesperson & -0.0572 & 0.0575 & -0.0075 & 0.1031 \\
\hline clerical-service & $-0.1235^{*}$ & 0.0661 & -0.0114 & 0.0468 \\
\hline production-transport & -0.0970 & 0.0804 & $-0.2695 * *$ & 0.1137 \\
\hline labourer & $-0.0998 *$ & 0.0758 & -0.0386 & 0.0836 \\
\hline never worked & 0.1754 & 0.2223 & 0.0997 & 0.1776 \\
\hline cut-off point $m_{0}$ & $-1.4507 * * *$ & 0.2470 & $-1.1076^{* * *}$ & 0.1972 \\
\hline cut-off point $m_{1}$ & -0.2439 & 0.2436 & 0.0671 & 0.2002 \\
\hline cut-off point $m_{2}$ & $1.0053^{* * *}$ & 0.2458 & $1.3427 * * *$ & 0.2018 \\
\hline cut-off point $m_{3}$ & $2.2311^{* * *}$ & 0.2495 & $2.5777 * * *$ & 0.2059 \\
\hline No of observations & & 3189 & & 3410 \\
\hline Log likelihood & & -3837.02 & & -4037.70 \\
\hline
\end{tabular}




\section{Continued}

\begin{tabular}{|c|c|c|c|c|}
\hline & \multicolumn{2}{|c|}{ Males 50-64 } & \multicolumn{2}{|c|}{ Females 50-60 } \\
\hline & Coefficient & Standard error & Coefficient & Standard error \\
\hline \multicolumn{5}{|c|}{ Labour force participation equation } \\
\hline health & $0.4105^{* * *}$ & 0.0582 & $0.4170 * * *$ & 0.0630 \\
\hline age/10 & $-0.9003 * * *$ & 0.1385 & $-0.8517 * * *$ & 0.1771 \\
\hline degree & $0.5488^{* * *}$ & 0.2070 & 0.2373 & 0.1488 \\
\hline other post-sch qual & -0.0233 & 0.1168 & -0.0091 & 0.1261 \\
\hline completed year 12 & -0.1696 & 0.2069 & 0.2092 & 0.2378 \\
\hline married & -0.1682 & 0.1443 & $-0.9629 * * *$ & 0.1460 \\
\hline spouse in labour force & $0.8675 * * *$ & 0.1255 & $1.0434 * * *$ & 0.1391 \\
\hline employment history & $7.4529 * * *$ & 1.0405 & $2.3017 * * *$ & 0.2141 \\
\hline unemployment history & $6.7282^{* * *}$ & 1.3582 & 1.8743 & 1.3167 \\
\hline indigenous & -0.2501 & 0.6216 & -0.1701 & 0.7064 \\
\hline born overseas & -0.0545 & 0.1363 & -0.1707 & 0.1510 \\
\hline born non-En country & 0.1816 & 0.1762 & -0.3114 & 0.1944 \\
\hline child $0-14$ & -0.2237 & 2.0544 & -0.4268 & 0.8172 \\
\hline married*child 0-14 & 0.3854 & 2.0789 & 0.3133 & 0.8743 \\
\hline constant & $-6.8182 * * *$ & 1.0152 & $-1.4627 * * *$ & 0.2324 \\
\hline Number of observations & & 1175 & & 940 \\
\hline Log likelihood & & -398.95 & & -394.84 \\
\hline \multicolumn{5}{|l|}{ Health equation } \\
\hline Labour force & -0.4848 & 0.5120 & $0.3591 *$ & 0.1850 \\
\hline age/10 & -0.2193 & 0.4260 & $0.3569 * *$ & 0.1793 \\
\hline degree & $0.8454^{* *}$ & 0.4287 & 0.1422 & 0.1198 \\
\hline other post-sch qual & 0.1111 & 0.0883 & $0.2162 * *$ & 0.0955 \\
\hline completed year 12 & 0.0564 & 0.1591 & 0.0192 & 0.1808 \\
\hline married & -0.2201 & 0.1445 & 0.2339 & 0.2320 \\
\hline spouse in labour force & 0.4585 & 0.4679 & -0.1654 & 0.2379 \\
\hline employment history & 4.3639 & 3.9742 & -0.6477 & 0.4617 \\
\hline unemployment history & 2.5565 & 3.3829 & -0.4127 & 1.3370 \\
\hline indigenous & -0.5932 & 0.5450 & 0.1662 & 0.5031 \\
\hline smoker & $-0.3395 * * *$ & 0.1300 & $-0.1553 * *$ & 0.0795 \\
\hline lack physical activity & -0.1955 & 0.1324 & $-0.3593 * * *$ & 0.0957 \\
\hline heavy drinker & 0.2129 & 0.1473 & -0.2308 & 0.5107 \\
\hline health condition & $-1.1381 * * *$ & 0.2158 & $-0.3886 * * *$ & 0.1343 \\
\hline physical functioning/100 & $2.9703^{* * *}$ & 0.7290 & $2.4838 * * *$ & 0.3626 \\
\hline tradesperson & -0.1383 & 0.1037 & -0.0460 & 0.2364 \\
\hline clerical-service & 0.1344 & 0.2022 & 0.1080 & 0.0935 \\
\hline production-transport & -0.1631 & 0.1338 & 0.0433 & 0.2252 \\
\hline labourer & -0.0974 & 0.1370 & -0.1386 & 0.1608 \\
\hline never worked & & & 0.3112 & 0.2998 \\
\hline cut-off point $m_{0}$ & 3.1241 & 3.7683 & $-0.9522 * *$ & 0.3993 \\
\hline cut-off point $m_{1}$ & 4.4135 & 3.7731 & 0.5018 & 0.4090 \\
\hline cut-off point $m_{2}$ & 5.8157 & 3.7760 & $1.9246^{* * *}$ & 0.4169 \\
\hline cut-off point $m_{3}$ & 7.1614* & 3.7771 & $3.2680 * * *$ & 0.4280 \\
\hline No of observations & & 1175 & & 940 \\
\hline Log likelihood & & -1328.78 & & -1048.57 \\
\hline
\end{tabular}

Note: a) Because predicted values were used in the second stage estimation, the standard method of calculating standard errors is no longer appropriate. In the table, the standard errors were bootstrapped with 1000 replications. 


\section{Tables}

Table 1: Labour force status ${ }^{\mathrm{a}}$ by self-assessed health status

\begin{tabular}{|c|c|c|c|c|c|}
\hline & Excellent (4) & Very good (3) & Good (2) & Fair (1) & Poor (0) \\
\hline \multicolumn{6}{|l|}{ Male } \\
\hline \% In labour force & 92.97 & 94.24 & 89.53 & 66.29 & 32.00 \\
\hline$\%$ Not in labour force & 7.03 & 5.76 & 10.47 & 33.71 & 68.00 \\
\hline Observations & 740 & 1736 & 1499 & 534 & 150 \\
\hline \multicolumn{6}{|l|}{ Male aged 15-49 } \\
\hline \% In labour force & 96.15 & 96.82 & 94.5 & 82.58 & 43.11 \\
\hline$\%$ Not in labour force & 3.85 & 3.18 & 5.51 & 17.42 & 56.9 \\
\hline Observations & 598 & 1321 & 1071 & 310 & 58 \\
\hline \multicolumn{6}{|l|}{ Male aged 50-64 } \\
\hline \% In labour force & 79.58 & 86.03 & 77.11 & 43.75 & 25 \\
\hline$\%$ Not in labour force & 20.42 & 13.98 & 22.9 & 56.25 & 75 \\
\hline Observations & 142 & 415 & 428 & 224 & 92 \\
\hline \multicolumn{6}{|l|}{ Female } \\
\hline \% In labour force & 78.65 & 77.86 & 69.35 & 51.90 & 26.83 \\
\hline$\%$ Not in labour force & 21.35 & 22.14 & 30.65 & 48.10 & 73.17 \\
\hline Observations & 862 & 1888 & 1527 & 499 & 123 \\
\hline \multicolumn{6}{|l|}{ Female aged $15-49$} \\
\hline \% In labour force & 79.46 & 78.46 & 72.34 & 59.34 & 37.18 \\
\hline$\%$ Not in labour force & 20.55 & 21.55 & 27.66 & 40.66 & 62.82 \\
\hline Observations & 730 & 1513 & 1157 & 332 & 78 \\
\hline \multicolumn{6}{|l|}{ Female 50-60 } \\
\hline \% In labour force & 74.24 & 75.46 & 60 & 37.13 & 8.89 \\
\hline$\%$ Not in labour force & 25.76 & 24.53 & 40 & 62.87 & 91.11 \\
\hline Observations & 132 & 375 & 370 & 167 & 45 \\
\hline
\end{tabular}

Note a: In labour force includes employed and unemployed persons. 


\section{Table 2: Variable definitions}

\section{Endogenous variables:}

$\begin{array}{ll}\text { labour force } & 1 \text { if in labour force } \\ \text { health } & \text { self-assessed health status, } 0=\text { =poor, 1=fair, 2=good, 3=very good, 4=excellent }\end{array}$

Variables appearing in both equations:

Demographic

age

age squared

married

indigenous

age deviation from a base age (a)

Education

degree

age deviation squared (a); only included for the younger age groups

1 if married or de facto

1 if indigenous or Torres Strait Islander

other post-sch qual 1 if has other non-degree post-school qualifications

completed year $12 \quad 1$ if completed year 12

Job history and spouse's labour force status

spouse in labour force 1 if married and the spouse in LF

employment history proportion of time (since leaving school) in employment

unemployment history proportion of time (since leaving school) in unemployment

Additional variables appearing in the labour force participation equation:

Demographic

born overseas

1 if born overseas

born non-En country

child 0-4

1 if born in non-English speaking foreign country

1 if has child(ren) under 4 years of age

child 5-14

1 if has child(ren) aged 5 to 14

child 0-14

1 if has child(ren) aged 0 to 14 (b)

married*child 0-4

married*child 5-14

interaction between married and child 0-4

interaction between married and child 5-14

married*child 0-14 interaction between married and child 0-14 (b)

\section{Additional variables appearing in the health equation:}

Occupation

tradesperson

clerical-service

production-transport

labourer

other occupations

never worked

Health related

smoker

health condition

lack physical activity

heavy drinker

physical functioning
1 if last or current job as a tradesperson or related worker

1 if last or current job as a clerical, sales or service worker

1 if last or current job as a production or transport worker

1 if last or current job as a labourer or related worker

1 if last or current job in an occupations other than those listed above

1 if never worked (c)

1 if currently smoking or ever smoked

1 if has long-term health conditions

1 if lack of physical activity, defined as no physical activity at all or less than once per week

1 if a heavy drinker, defined as drinking more than 6 standard drinks a day when drinking Index of physical functioning

Note a: The age variable enters the model as a deviation. For the younger groups, the difference between the actual age and 15 enters the model estimation. For the older groups, the difference between the actual age and 50 enters the model estimation. A similar deviation applies to the age squared variable.

b: The reason that child 0-14 and married*child 0-14 are used for older people in place of child 0-4, child 5-14, married*child $0-4$, and married*child 5-14 is that among the older age groups, few people have a child younger than 5 years of age. There are no males aged 50 or over having a child younger than 5 years. Only a few females aged 50 or over have a child younger than 5 years.

c: The variable, never worked, is excluded from the health equation for older men, because only one person has never worked in this group. This observation is excluded from estimation. 
Table 3: Descriptive statistics of the sample

\begin{tabular}{|c|c|c|c|c|c|c|c|c|}
\hline \multirow{3}{*}{$\frac{\text { Variable }}{\text { Endogenous variables }}$} & \multicolumn{2}{|c|}{ Males 15-49 } & \multirow{2}{*}{\multicolumn{2}{|c|}{$\begin{array}{l}\text { Females 15-49 } \\
\text { Mean Std.Dev. }\end{array}$}} & \multirow{2}{*}{\multicolumn{2}{|c|}{$\begin{array}{r}\text { Males 50-64 } \\
\text { Mean Std.Dev. }\end{array}$}} & \multicolumn{2}{|c|}{ Females 50-60 } \\
\hline & \multicolumn{2}{|c|}{ Mean Std.Dev. } & & & & & Mean & Std.Dev. \\
\hline & & & \multirow{2}{*}{0.75} & \multirow[b]{2}{*}{0.43} & \multirow{3}{*}{0.71} & \multirow[b]{2}{*}{0.45} & \multirow[b]{2}{*}{0.62} & \multirow[b]{2}{*}{0.49} \\
\hline labour force & 0.94 & 0.23 & & & & & & \\
\hline health & 2.63 & 0.93 & 2.65 & 0.95 & & 1.07 & 2.38 & 1.01 \\
\hline \multicolumn{9}{|l|}{ Demographic } \\
\hline age & 35.02 & 8.73 & 34.91 & 8.47 & 56.43 & 4.24 & 54.57 & 3.11 \\
\hline married & 0.65 & 0.48 & 0.68 & 0.47 & 0.81 & 0.39 & 0.74 & 0.44 \\
\hline child 0-4 & 0.22 & 0.41 & 0.25 & 0.43 & 0.02 & 0.13 & 0.00 & 0.03 \\
\hline child 5-14 & 0.30 & 0.46 & 0.39 & 0.49 & 0.09 & 0.29 & 0.05 & 0.22 \\
\hline child 0-14 & 0.43 & 0.50 & 0.53 & 0.50 & 0.10 & 0.30 & 0.05 & 0.22 \\
\hline married*child 0-4 & 0.21 & 0.41 & 0.21 & 0.41 & 0.02 & 0.13 & 0.00 & 0.03 \\
\hline married*child 5-14 & 0.29 & 0.45 & 0.32 & 0.47 & 0.08 & 0.28 & 0.04 & 0.19 \\
\hline married ${ }^{*}$ child 0-14 & 0.42 & 0.49 & 0.44 & 0.50 & 0.09 & 0.29 & 0.04 & 0.19 \\
\hline born overseas & 0.21 & 0.41 & 0.21 & 0.41 & 0.33 & 0.47 & 0.29 & 0.45 \\
\hline born non-En country & 0.11 & 0.31 & 0.12 & 0.33 & 0.17 & 0.37 & 0.15 & 0.36 \\
\hline indigenous & 0.02 & 0.12 & 0.02 & 0.16 & 0.01 & 0.09 & 0.01 & 0.10 \\
\hline \multicolumn{9}{|l|}{ Education } \\
\hline degree & 0.21 & 0.41 & 0.26 & 0.44 & 0.19 & 0.39 & 0.20 & 0.40 \\
\hline other post-s & 0.46 & 0.50 & 0.34 & 0.47 & 0.43 & 0.50 & 0.30 & 0.46 \\
\hline year 12 & 0.12 & 0.32 & 0.14 & 0.35 & 0.08 & 0.27 & 0.06 & 0.24 \\
\hline lower than year 12 & 0.21 & 0.41 & 0.26 & 0.44 & 0.30 & 0.46 & 0.44 & 0.50 \\
\hline \multicolumn{9}{|c|}{ Occupation, job history and spouse's labour force status } \\
\hline tradesperson & 0.22 & 0.41 & 0.04 & 0.20 & 0.13 & 0.34 & 0.02 & 0.15 \\
\hline clerical-service & 0.14 & 0.34 & 0.44 & 0.50 & 0.14 & 0.35 & 0.40 & 0.49 \\
\hline ction-transport & 0.13 & 0.33 & 0.03 & 0.17 & 0.14 & 0.35 & 0.05 & 0.22 \\
\hline labourer & 0.11 & 0.32 & 0.09 & 0.28 & 0.10 & 0.30 & 0.13 & 0.34 \\
\hline other occupation & 0.41 & 0.49 & 0.41 & 0.49 & 0.48 & 0.50 & 0.39 & 0.49 \\
\hline spouse in labour force & 0.47 & 0.50 & 0.64 & 0.48 & 0.51 & 0.50 & 0.51 & 0.50 \\
\hline employment history & 0.87 & 0.21 & 0.71 & 0.29 & 0.93 & 0.12 & 0.66 & 0.28 \\
\hline unemployment history & 0.05 & 0.13 & 0.04 & 0.12 & 0.02 & 0.05 & 0.01 & 0.04 \\
\hline never worked & 0.01 & 0.11 & 0.02 & 0.16 & & & 0.01 & 0.11 \\
\hline \multicolumn{9}{|l|}{ Health related } \\
\hline smoker & 0.56 & 0.50 & 0.50 & 0.50 & 0.63 & 0.48 & 0.44 & 0.50 \\
\hline health condition & 0.17 & 0.38 & 0.14 & 0.35 & 0.35 & 0.48 & 0.28 & 0.45 \\
\hline lack physical activity & 0.23 & 0.42 & 0.29 & 0.45 & 0.28 & 0.45 & 0.28 & 0.45 \\
\hline heavy drinker & 0.15 & 0.36 & 0.05 & 0.22 & 0.05 & 0.22 & 0.01 & 0.10 \\
\hline ning & 89.76 & 18.46 & 88.11 & 18.38 & 78.34 & 24.29 & 77.94 & 23.27 \\
\hline No of observations & 3189 & & 3410 & & 1175 & & 940 & \\
\hline
\end{tabular}


Table 4: Full information maximum likelihood results

\begin{tabular}{|c|c|c|c|c|}
\hline & \multicolumn{2}{|c|}{ Males 15-49 } & \multicolumn{2}{|c|}{ Females 15-49 } \\
\hline & \multicolumn{2}{|c|}{ Coefficient Standard error } & Coefficient & Standard error \\
\hline \multicolumn{5}{|c|}{ Labour force participation - equation (5) } \\
\hline health & $0.8198 * * *$ & 0.1201 & $0.3501 * * *$ & 0.0398 \\
\hline age/10 & -0.0152 & 0.2017 & $-0.6938 * * *$ & 0.184 \\
\hline age squared/100 & -0.027 & 0.0512 & $0.1539 * * *$ & 0.0458 \\
\hline degree & $0.4383 * * *$ & 0.1531 & $0.5291 * * *$ & 0.0855 \\
\hline other post-sch qual & 0.0644 & 0.1009 & $0.1959 * * *$ & 0.071 \\
\hline completed year 12 & 0.2496 & 0.1661 & 0.0353 & 0.0949 \\
\hline married & -0.103 & 0.1245 & $-0.5529 * * *$ & 0.1421 \\
\hline spouse in labour force & $0.3522 * * *$ & 0.1249 & $0.4322 * * *$ & 0.1171 \\
\hline employment history & $2.0623 * * *$ & 0.2188 & $2.0218 * * *$ & 0.1216 \\
\hline unemployment history & $1.4939 * * *$ & 0.3166 & $1.0569 * * *$ & 0.2421 \\
\hline indigenous & 0.0056 & 0.4559 & 0.0861 & 0.1407 \\
\hline born overseas & $-0.2576 * *$ & 0.1019 & -0.0795 & 0.0906 \\
\hline born non-En country & -0.0105 & 0.1208 & -0.029 & 0.1116 \\
\hline child 0-4 & $-1.3799 * * *$ & 0.496 & $-0.9852 * * *$ & 0.1274 \\
\hline child 5-14 & -0.1749 & 0.2059 & $-0.3252 * * *$ & 0.1181 \\
\hline married*child 0-4 & $1.5100 * * *$ & 0.5029 & -0.1614 & 0.1424 \\
\hline married*child 5-14 & 0.2018 & 0.2188 & $0.4541 * * *$ & 0.1297 \\
\hline constant & $-1.5763 * * *$ & 0.3756 & -0.2746 & 0.1815 \\
\hline \multicolumn{5}{|l|}{ Health - equation (4) } \\
\hline Labour force & $-0.7186 * * *$ & 0.1657 & 0.0113 & 0.0415 \\
\hline age/10 & -0.1288 & 0.1619 & $0.2321 * *$ & 0.1137 \\
\hline age squared/100 & -0.0314 & 0.0412 & $-0.0755^{* * *}$ & 0.029 \\
\hline degree & $0.6423 * * *$ & 0.1307 & $0.1568 * *$ & 0.0682 \\
\hline other post-sch qual & $0.1924 * *$ & 0.081 & $0.1170^{* *}$ & 0.0528 \\
\hline completed year 12 & $0.4112^{* * *}$ & 0.1331 & $0.1765 * * *$ & 0.0632 \\
\hline married & -0.0373 & 0.0915 & 0.0846 & 0.1072 \\
\hline spouse in labour force & $0.3928 * * *$ & 0.1077 & 0.0504 & 0.1024 \\
\hline employment history & $1.9391 * * *$ & 0.3678 & 0.1933 & 0.1229 \\
\hline unemployment history & $1.1792 * * *$ & 0.3349 & -0.0636 & 0.1633 \\
\hline indigenous & $0.6010 *$ & 0.3487 & -0.0632 & 0.099 \\
\hline smoker & $-0.2475^{* * *}$ & 0.0484 & $-0.2819 * * *$ & 0.0384 \\
\hline lack physical activity & $-0.3514 * * *$ & 0.055 & $-0.3781^{* * *}$ & 0.0415 \\
\hline heavy drinker & $-0.1741^{* * *}$ & 0.0676 & 0.0915 & 0.0825 \\
\hline health condition & $-0.8998 * * *$ & 0.0698 & $-0.9029 * * *$ & 0.0549 \\
\hline physical functioning/100 & $1.7006 * * *$ & 0.1211 & $1.6605^{* * *}$ & 0.0913 \\
\hline tradesperson & -0.082 & 0.0694 & -0.0622 & 0.1021 \\
\hline clerical-service & $-0.1343^{*}$ & 0.0738 & -0.0433 & 0.0495 \\
\hline production-transport & $-0.1563 *$ & 0.0801 & $-0.2848 * * *$ & 0.1087 \\
\hline labourer & $-0.1380 *$ & 0.0828 & -0.1067 & 0.0766 \\
\hline never worked & 0.0874 & 0.1955 & -0.022 & 0.1185 \\
\hline cut-off point $m_{0}$ & -0.4195 & 0.37 & $-1.1700 * * *$ & 0.1701 \\
\hline cut-off point $m_{1}$ & $0.5200 *$ & 0.2743 & 0.0108 & 0.1564 \\
\hline cut-off point $m_{2}$ & $1.4877^{* * *}$ & 0.213 & $1.2878^{* * *}$ & 0.1562 \\
\hline cut-off point $m_{3}$ & $2.4357 * * *$ & 0.2222 & $2.5215^{* * *}$ & 0.1562 \\
\hline correlation $\rho$ & 0.0086 & 0.1768 & $-0.3117 * * *$ & 0.0643 \\
\hline No of observations & & 3189 & & 3410 \\
\hline Log likelihood & & -4268.57 & & -5332.11 \\
\hline
\end{tabular}


Table 4: Full information maximum likelihood results (continued)

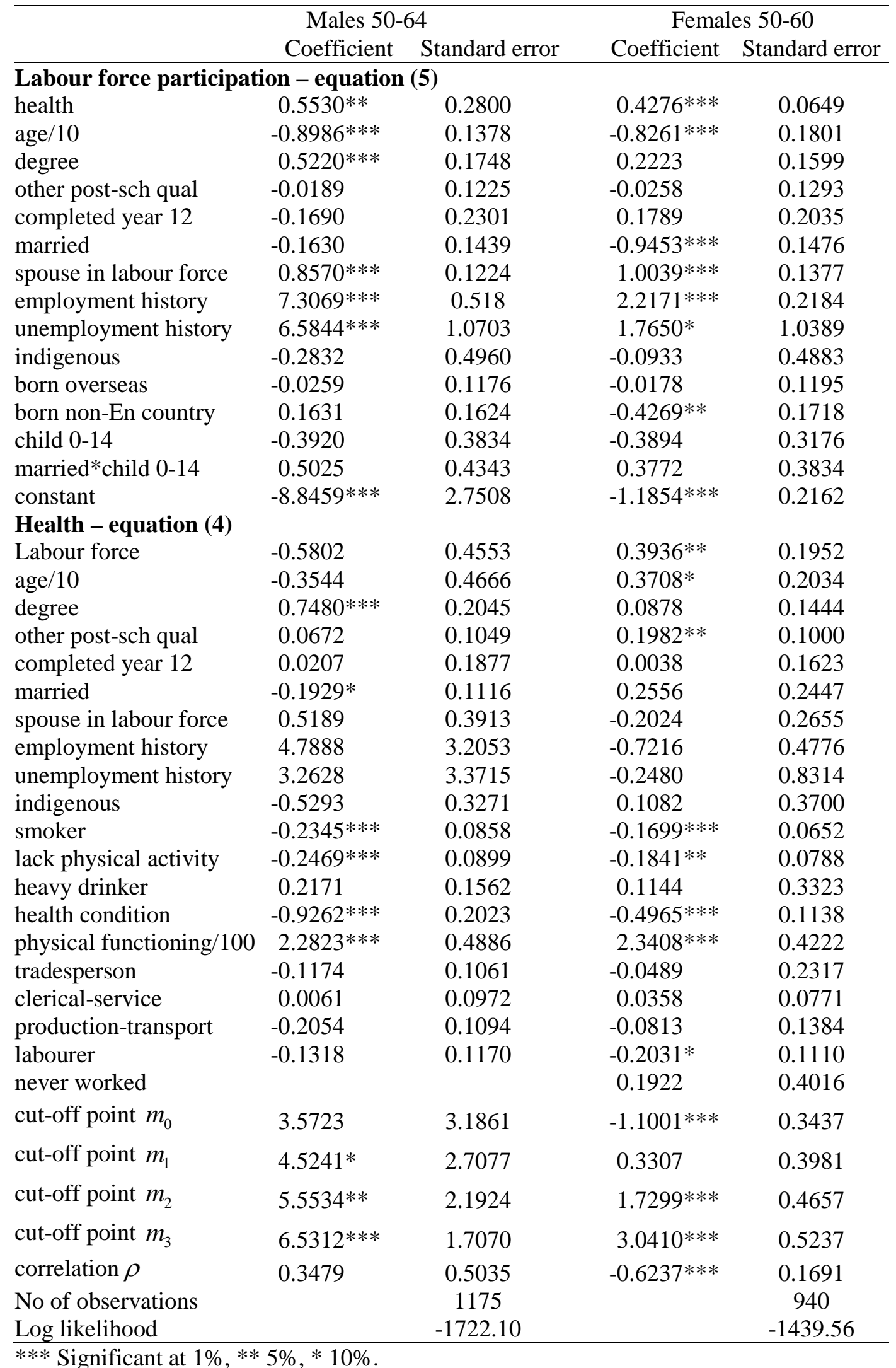


Table 5: Predicted conditional probability of labour force participation

\begin{tabular}{lccc}
\hline Health status & $\begin{array}{c}\text { Predicted } \\
\text { probability of } \\
\text { LFP }\end{array}$ & $\begin{array}{c}\text { \% change } \\
\text { compared with } \\
\text { higher health } \\
\text { status }\end{array}$ & $\begin{array}{c}\text { \% change } \\
\text { compared with } \\
\text { excellent health }\end{array}$ \\
\hline Males 15-49 & & & \\
Poor & 0.9279 & -0.7117 & -2.4318 \\
Fair & 0.9345 & -0.6254 & -1.7325 \\
Good & 0.9404 & -0.5676 & -1.1140 \\
Very good & 0.9458 & -0.5496 & -0.5496 \\
Excellent & 0.9510 & & \\
Males 50-64 & & & -20.8982 \\
Poor & 0.6206 & -6.9959 & -14.9481 \\
Fair & 0.6672 & -5.9806 & -9.5380 \\
Good & 0.7097 & -5.1719 & -4.6042 \\
Very good & 0.7484 & -4.6042 & \\
Excellent & 0.7845 & & -6.5343 \\
Females 15-49 & & & -4.8579 \\
Poor & 0.7194 & -1.7619 & -3.2187 \\
Fair & 0.7323 & -1.6937 & -1.6493 \\
Good & 0.7449 & -1.5957 & \\
Very good & 0.7570 & -1.6493 & -25.3216 \\
Excellent & 0.7697 & & -11.6803 \\
Females 50-60 & & & \\
Poor & 0.5139 & -8.7908 & \\
Fair & 0.5634 & -7.2959 & \\
Good & 0.6077 & -6.2596 & \\
Very good & 0.6483 & -5.7828 & \\
Excellent & 0.6881 & & \\
\hline
\end{tabular}


Table 6: Test for exogeneity

Males 15-49 Females 15-49 Males 50-64 Females 50-60

\begin{tabular}{lllll}
\hline$\chi^{2}(2)$ & 59.91 & 35.45 & 12.92 & 30.94 \\
\hline
\end{tabular}

Note: all statistics are significant at the 5 percent level. 
Table 7: Comparison of coefficients on the endogenous variables

\begin{tabular}{lcccc}
\hline \multicolumn{2}{c}{ FIML estimation } & \multicolumn{2}{c}{ Two-stage estimation } \\
& Coefficient & Standard error & Coefficient & Standard error \\
\hline Males 15-49 & & & & \\
Health & $0.8198^{* * *}$ & 0.1201 & $0.7467^{* * *}$ & 0.0821 \\
Labour force & $-0.7186^{* * *}$ & 0.1657 & -0.0301 & 0.1054 \\
Female 15-49 & & & & \\
Health & $0.3501^{* * *}$ & 0.0398 & $0.3581^{* * *}$ & 0.0486 \\
Labour force & 0.0113 & 0.0415 & 0.0113 & 0.0368 \\
Males 50-64 & & & & \\
Health & $0.5530^{* *}$ & 0.2800 & $0.4105^{* * *}$ & 0.0582 \\
Labour force & -0.5802 & 0.4553 & -0.4848 & 0.5120 \\
Female 50-60 & & & & \\
Health & $0.4276^{* * *}$ & 0.0649 & $0.4170^{* * *}$ & 0.0630 \\
Labour force & $0.3936^{* *}$ & 0.1952 & $0.3591^{*}$ & 0.1850 \\
\hline Note: Coefficients are not comparable across groups (see Section 2.2$).$
\end{tabular}

